\title{
Tracheostomy timing in traumatic spinal cord injury
}

\author{
Javier Romero · Alessandra Vari • \\ Claudia Gambarrutta $\cdot$ Antonio Oliviero
}

Received: 10 January 2008/Revised: 24 June 2009/ Accepted: 5 July 2009/Published online: 5 August 2009

(C) Springer-Verlag 2009

\begin{abstract}
The study conducted is the retrospective study and the main objective is to evaluate the benefits and safety of early versus late tracheostomy in traumatic spinal cord injury (SCI) patients requiring mechanical ventilation. Tracheostomy offers many advantages in critical patients who require prolonged mechanical ventilation. Despite the large amount of patients treated, there is still an open debate about advantages of early versus late tracheostomy. Early tracheostomy following the short orotracheal intubation is probably beneficial in appropriately selected patients. It is a retrospective clinical study and we evaluated clinical records of 152 consecutive trauma patients who required mechanical ventilation and who received tracheostomy. The results show that the early placement (before day 7 of mechanical ventilation) offers clear advantages for shortening of mechanical ventilation, reducing ICU stay and lowering rates of severe orotracheal intubation complication, such as tracheal granulomas and concentric tracheal stenosis. On the other hand, we could not demonstrate that early tracheostomy avoids neither risk of ventilator-associated pneumonia nor the mortality rate. In SCI patients, the early tracheostomy was associated with shorter duration of mechanical ventilation, shorter length of ICU stay and decreased laryngotracheal complications. We conclude by suggesting early tracheostomy in traumatic
\end{abstract}

J. Romero $(\varangle) \cdot$ C. Gambarrutta · A. Oliviero Intensive Care Unit and Neurology Unit, UCI, Hospital Nacional de Paraplejicos,

Finca "La Peraleda" s/n, 45071 Toledo, Spain

e-mail: fjromero@sescam.jccm.es

A. Vari

Dipartimento di Anestesia, Rianimazione,

Medicina Critica e Terapia del Dolore,

Universita' "La Sapienza", Rome, Italy
SCI patients who are likely to require prolonged mechanical ventilation.

Keywords Tracheostomy - Spinal cord injury · Mechanical ventilation

\section{Introduction}

Tracheostomy is one of the most commonly performed procedures in the intensive care unit (ICU) [1]. The goal of performing this technique is to improve the artificial ventilator support through a drop dead space, facilitate bronchial clearance, avoid complications of prolonged orotracheal intubation, facilitate weaning from mechanical ventilation, support phonation and swallowing, and reduce the length of sedation to prevent related complications [2]. As an invasive procedure, it might cause severe airway stenosis and other complications.

A significant proportion of patients with cervical as well as thoracic SCI require placement of a tracheostomy due to prolonged mechanical ventilation and to facilitate bronchial cleaning. This technique is required more frequently in cases of higher spinal cord injury level and ASIA severity scale. Tracheostomy plays an integral role in the airway management of such patients, but its timing remains to be the subject to considerable variation [3]. Subsequent long-term dependence on mechanical ventilation is common in patients with high-cervical SCI [4].

There is still an open debate regarding the appropriate timing of tracheostomy in injured patients who require prolonged mechanical ventilation. Although general guidelines suggest that tracheostomy should be considered after an initial period of stabilization on the ventilator (generally the first 7 days), there is no evidence on its 
optimal timing, and a practical decision has to be made for each individual patient with the consideration of expected benefits and risks if the translaryngeal intubation is anticipated to be needed longer [5, 6].A recent meta-analysis of the efficacy of early tracheostomy reported that patients treated with early definitive airway placement could benefit from the reduction of mechanical ventilation and ICU stay, while there were no changes in the rate of pneumonia or mortality [7]. Therefore, we decided to perform a retrospective study to evaluate its efficacy and safety of early versus late tracheostomy in patients with traumatic spinal cord injury requiring prolonged mechanical ventilation.

\section{Patients and methods}

\section{Settings and patients}

The present study was performed in a seven-bed ICU in the Hospital Nacional de Paraplejicos, Toledo, Spain. It is a specialized hospital for patients with medical and traumatic spinal cord injury (SCI). Medical records of all new patients with traumatic SCI in acute or subacute stage admitted to the ICU between 01 May 2004 and 30 April 2007 have been retrospectively reviewed. We evaluated a total of 164 patients. The data from 12 patients were excluded from analysis: ten patients with cervical spine injury above $\mathrm{C} 3$ who required permanent ventilation with no possibility of weaning, one patient with severe maxillofacial traumatic injury comprising the airway, and one patient with the missing data. Therefore, we analyzed data from a total of 152 patients whose clinical and demographic data are summarized in Table 1.

\section{Clinical definitions and parameters of study}

Early tracheotomy was defined as performed in days 1-7 after orotracheal intubation and late if it was performed any time after the early tracheostomy [8]. The decision to perform a tracheostomy was made for each individual patient based on the judgment of the attending physician who is expert in ICU, in discussion with the patient's family members, without definite protocolized criteria to decide when is the best time to perform the procedure. The diagnosis of pneumonia required radiographic image of a new and persistent infiltrate and at least two of the following criteria: temperature above $38^{\circ} \mathrm{C}$. or below $35.5^{\circ} \mathrm{C}$, leukocytes above 12,000 cells $/ \mathrm{mm}^{3}$ or below 4,000 cells/ $\mathrm{mm}^{3}$, new onset of purulent bronchial secretions or change in its character.

The following parameters were recorded, such as mortality rate, duration of mechanical ventilation (total time and time post tracheostomy), length of stay in the ICU
Table 1 Patient characteristics and clinical data for study cohort

\begin{tabular}{|c|c|}
\hline \multicolumn{2}{|l|}{ Sex } \\
\hline Male & $n=122,80.2 \%$ \\
\hline Female & $n=30,19.8 \%$ \\
\hline \multicolumn{2}{|l|}{ Age } \\
\hline Mean and range & 41 years; $13-77$ years \\
\hline Median & 38.5 years \\
\hline \multicolumn{2}{|l|}{ Spine injury cause } \\
\hline Traffic trauma & $n=96,64 \%$ \\
\hline Fall injuries & $n=42,28 \%$ \\
\hline External trauma & $n=8,5.3 \%$ \\
\hline Gunshot wound & $n=2,1.3 \%$ \\
\hline Others & $n=2,1.3 \%$ \\
\hline \multicolumn{2}{|l|}{ Spine injury level } \\
\hline $\mathrm{C} 3-\mathrm{C} 5$ & $79,51.97 \%$ \\
\hline $\mathrm{C} 6-\mathrm{C} 8$ & $42,27.63 \%$ \\
\hline D1-D5 & $22,14.47 \%$ \\
\hline D6-D10 & $9,5.92 \%$ \\
\hline \multicolumn{2}{|l|}{ Spine injury grade } \\
\hline ASIA A & $n=119,78.28 \%$ \\
\hline ASIA B & $n=21,13.82 \%$ \\
\hline ASIA C & $n=11,7.24 \%$ \\
\hline ASIA D & $n=1,0.66 \%$ \\
\hline \multicolumn{2}{|l|}{ APACHE II } \\
\hline Mean and range & $7.48,6.73-8.24$ \\
\hline Median & 7 \\
\hline \multicolumn{2}{|l|}{ ISS } \\
\hline Mean and range & $29.28,28.13-30.44$ \\
\hline Median & 25 \\
\hline
\end{tabular}

ASIA grade: severity score according to the American Spinal Injury Association [25] APACHE II acute physiology and chronic health evaluation II, ISS injury severity score

(total time and time post tracheostomy), and incidence of pneumonia. We also evaluated the complications of tracheostomy in both the groups.

Data presentation and statistical analysis

Our patients were divided into two groups: those that underwent early tracheostomy, performed in days 0-7 after intubation, and late tracheostomy, performed after the seventh day. The comparison of both groups was carried out using the statistical package SPSS vs. 13.0. Continuous variables were expressed as mean \pm standard deviation (SD) and were compared using Student's $t$ test. Outliers and extreme values were expressed as median. Categorical variables were expressed as absolute and relative frequency and compared using the $\chi^{2}$ test.

Multivariate analyses were performed to evaluate the impact of timing of tracheostomy on duration of 
mechanical ventilation (both total time and time post tracheostomy), length of stay in the ICU (total time and time post tracheostomy), and incidence of tracheostomy complications, to determine whether these factors are independent in predicting prolonged mechanical ventilation, ICU stay, and a higher rate of tracheostomy complications. These results were expressed as odds ratio (OR) with $95 \%$ confidence interval. $P \leq 0.05$ was considered statistically significant.

\section{Results}

We have reviewed 152 consecutive medical records of the patients who had undergone tracheostomy. The average age in these patients was 41 years, with range 13-77 years. The main cause of SCI was traffic accidents. Time range between injury and admission to the ICU was 2-103 days with mean time equal to 27.4 days and median time of 24 days. Others demographic and clinical characteristics are displayed in Table 1.

Tracheostomy was placed early (days 1-7 from intubation) in 71 patients and late (after day 7) in 81 cases. We will refer to the two groups as early tracheotomy group (ETG) and late tracheostomy group (LTG). Tracheostomy was performed according to the standard surgical technique in 83 patients and percutaneously in 69 cases.

The comparison of demographic variables was not statistically significant for the groups of early and late placement, except for the age that was significantly younger for ETG. There were no statistically significant differences in severity of illness, lesion level and lesion grade of both groups (Table 2). Similarly, no significant difference was observed between the two groups with respect to mortality, although we observed a trend towards reduction in mortality rate in the ETG ( 1 vs. 5 patients in the early vs. LTG) that was not statistically significant (Table 3).

The ETG patients had statistically significant shorter mechanical ventilation (both as total time and when we considered only the post tracheostomy time) (see Table 3). Moreover, the patients of ETG had a statistically significantly reduced length of ICU stay with respect to LTG, both as total time and when we considered only the post tracheostomy time (see Table 3). Regarding the incidence of pneumonia, we observed that the number of patients who suffered pneumonia, both pre and post tracheostomy, is not different in both the groups ( 87.3 vs. $92.7 \%$ ), but if considering only the difference during the intubation period and after tracheostomy period, the prevalence of pneumonia is lower in ETG versus LTG.

Multivariate analysis with multiple logistic regression revealed that only duration of mechanical ventilation is
Table 2 Demographics and clinical data of patients according to tracheostomy placement time

\begin{tabular}{|c|c|c|c|}
\hline & $\begin{array}{l}\text { Early } \\
\text { tracheostomy }\end{array}$ & $\begin{array}{l}\text { Late } \\
\text { tracheostomy }\end{array}$ & $P$ \\
\hline Patients & $n=71$ & $n=81$ & \\
\hline \multicolumn{4}{|l|}{ Sex } \\
\hline Male & $n=57$ & $n=65$ & \multirow[t]{2}{*}{0.85} \\
\hline Female & $n=14$ & $n=16$ & \\
\hline Mean age & $38.06 \pm 1.87$ & $43.66 \pm 1.85$ & $<0.05$ \\
\hline \multicolumn{4}{|c|}{ Level of spine lesion } \\
\hline C3C5 & 42 & 37 & \multirow[t]{4}{*}{0.10} \\
\hline С6C8 & 19 & 23 & \\
\hline D1D5 & 9 & 13 & \\
\hline D6D12 & 1 & 8 & \\
\hline \multicolumn{4}{|l|}{ ASIA grade } \\
\hline A & 55 & 64 & \multirow[t]{4}{*}{0.14} \\
\hline B & 4 & 10 & \\
\hline $\mathrm{C}$ & 11 & 7 & \\
\hline $\mathrm{D}$ & 1 & 0 & \\
\hline APACHE II & $6.86 \pm 0.4$ & $8.04 \pm 0.63$ & 0.11 \\
\hline ISS & $28.47 \pm 0.87$ & $29.99 \pm 0.80$ & 0.20 \\
\hline \multicolumn{4}{|c|}{ Fixation cervical spinal surgery } \\
\hline Yes & 55 & 51 & \multirow[t]{2}{*}{0.08} \\
\hline No & 16 & 30 & \\
\hline \multicolumn{4}{|c|}{ Tracheostomy type } \\
\hline Percutaneous & 32 & 37 & \multirow[t]{2}{*}{0.93} \\
\hline Surgical & 39 & 44 & \\
\hline
\end{tabular}

ASIA grade: severity score according to the American Spinal Injury Association [25]; APACHE II acute physiology and chronic health evaluation II; ISS injury severity score

Table 3 Clinical data of patients according to tracheostomy placement time

\begin{tabular}{|c|c|c|c|}
\hline & $\begin{array}{l}\text { Early } \\
\text { tracheostomy } \\
n=71\end{array}$ & $\begin{array}{l}\text { Late } \\
\text { tracheostomy } \\
n=81\end{array}$ & $P$ \\
\hline $\begin{array}{l}\text { Pneumonia during } \\
\text { intubation }\end{array}$ & $n=32(45.1 \%)$ & $n=66(81.5 \%)$ & $<0.001$ \\
\hline $\begin{array}{l}\text { Pneumonia post } \\
\text { tracheostomy }\end{array}$ & $n=53(74.6 \%)$ & $n=59(72.8 \%)$ & 0.8 \\
\hline Total pneumonia & $n=62(87.3 \%)$ & $n=76(92.7 \%)$ & 0.27 \\
\hline Mortality & $n=1$ & $n=5$ & 0.12 \\
\hline $\begin{array}{l}\text { Total time of MV } \\
\text { (days) }\end{array}$ & $26.07 \pm 1.69$ & $48.75 \pm 3.45$ & $<0.001$ \\
\hline $\begin{array}{l}\text { Post tracheostomy } \\
\text { MV (days) }\end{array}$ & $22.14 \pm 1.18$ & $33.96 \pm 3.30$ & $<0.005$ \\
\hline $\begin{array}{l}\text { Total ICU stay } \\
\text { (days) }\end{array}$ & $36.52 \pm 1.59$ & $54.58 \pm 2.92$ & $<0.001$ \\
\hline $\begin{array}{l}\text { Post tracheostomy } \\
\text { ICU stay (days) }\end{array}$ & $30.60 \pm 1.64$ & $39.27 \pm 2.95$ & $<0.05$ \\
\hline
\end{tabular}

$M V$ mechanical ventilation, $I C U$ intensive care unit 
Table 4 Tracheostomy complications

\begin{tabular}{lccr}
\hline & $\begin{array}{l}\text { Early } \\
\text { tracheostomy }\end{array}$ & $\begin{array}{l}\text { Late } \\
\text { tracheostomy }\end{array}$ & $P$ \\
\hline Total complications & $22(30.99 \%)$ & $42(51.85 \%)$ & $<0.05$ \\
Bleeding & 4 & 6 & 0.75 \\
Stoma infection & 14 & 10 & 0.08 \\
Suture dehiscences & 1 & 3 & 0.28 \\
Granuloma & $2(2.81 \%)$ & $10(12.34 \%)$ & $<0.05$ \\
Concentric tracheal stenosis & $1(1.41 \%)$ & $13(16.03 \%)$ & $<0.01$ \\
\hline
\end{tabular}

identifiable as independent variable associated with early tracheostomy, whether we considered the total time of mechanical ventilation $(P<0.005$ and OR $6.73[2.42-$ 16.61]) or only the time of post tracheostomy $(P<0.005$ and 5.88 [2.33-14.28]).

The complications of the procedure in our patients are summarized in Table 4. The total number of complications was higher in patients who received a delayed versus early tracheostomy (51.85 vs. $30.99 \%$ ). The higher complication rate in LTG is due to the greater presence of concentric tracheal stenosis and tracheal granuloma in this group. Multivariate analysis showed that only tracheal stenosis was associated as independent variable to late tracheostomy placement with $P<0.001$ and OR 14.28 (2.27-83).

\section{Discussion}

Tracheostomy plays an important role in the airway management of SCI patients, both cervical and thoracic. The beneficial effects of this technique are improved respiration, facilitated weaning by reducing the airway resistance, reduced mortality rate, and prevention of complications of prolonged orotracheal intubation, such as oropharyngeal, laryngeal, and tracheal stenosis or fistulae $[9,10]$. Although it is an invasive procedure with intrinsic risks, additional benefits include the facilitation of nursing care, possibility of suctioning of respiratory secretions, and improving patients' comfort, swallowing and early phonation [11, 12].

Patients with SCI frequently need prolonged mechanical ventilation due to paralysis of respiratory muscles (in cervical lesions) and worsening pulmonary vital capacity (in lower as well as higher levels of injury), severe impairment of tracheobronchial secretions clearance, and high incidence of respiratory complications such as pneumonia or atelectasis, that arise in $40-70 \%$ of the patients with cervical spine lesions [13]. For these reasons, tracheostomies are frequently performed in these patients with the aim of avoiding possible airway lesions from prolonged intubation, easing nursing care, improving comfort, facilitating tracheobronchial clearance, supporting weaning from mechanical ventilation, and allowing speech and oral nutrition $[3,14,15]$. The consensus conference on artificial airway in mechanically ventilated patients sponsored by ACCP on 1989 issued the statement that tracheostomy is preferred over intubation only in cases of expected prolonged mechanical ventilation (longer that 21 days) [5], even though it is possible to advance the performance of this technique when it becomes apparent that the patient will require prolonged ventilation assistance [6].

Optimal timing of tracheostomy in SCI, as well as in other critical illnesses, remains a subject of debate due to the lack of strong evidence in support of when it is most advisable to perform it [2]. There are some general guidelines, but in the clinical practice the decision should be adopted for each patient with the careful consideration of possible benefits and risks. In the last few years, early tracheostomy has become the most recommended strategy for mechanically ventilated patients, chiefly due to the growing evidence of its low morbility and morbidity, and because of the identification of prolonged intubations as the main risk for multiple complications. Increased popularity of the percutaneous technique, safe and efficacious, has also contributed to promote early tracheostomy placement, while indications for tracheostomy have not changed in the clinical practice [16-18].

Many authors have reported that early tracheostomy placement is associated with a marked reduction in ICU stay and/or in the duration of mechanical ventilation in patients admitted to an ICU with medical illnesses, polytrauma, and in surgical and neurosurgical patients. In spite of that there are also studies leading to controversial conclusions: neither in head injury trauma patients, nor in critical patients with thermal injuries, has early tracheostomy shown any clear advantage in shortening mechanical ventilation $[6,19,20]$.

We are aware that a retrospective study could have some limitations, but the best of our knowledge; this is the first report on tracheostomy timing in SCI population. The main characteristics of both groups are similar and the small difference of age could be considered negligible. Because of this, we selected a limited number of end points in order to minimize false associations within both the groups of the tracheostomized patients.

To our knowledge, no data are available in SCI population about the timing of tracheostomy. It is an intervention of great importance in SCI patients, since respiratory complications raise ICU length of stay (27 days on average) [15]. In our series, we first report an apparent shortening in ICU stay and a marked reduction in the duration of mechanical ventilation for those patients who had undergone early versus late tracheostomy. Some authors evidenced how early tracheostomy also lowers ICU mortality rate [14] and the overall hospital mortality [21]. Others 
reported a mortality rate reduction on a long-term basis, but not on a short term [18]. These observations were not confirmed by other authors who could not demonstrate any significant association between early tracheostomy and reduction of mortality rate in surgical, polytrauma, and severe head injury patients [7, 20, 22, 23]. In SCI population, we found a tendency towards the reduction of mortality rate that was $6.2 \%$ in LTG and $1.4 \%$ in the ETG. The lack of statistical significance could probably be explained by the relatively low-mortality rate in subacute phase of SCI and relatively low number of patients included in the study.

It has been suggested that early tracheostomy might lower the rate of ventilator-associated pneumonia (VAP) due to reduced colonization of the tracheobronchial tract. This point is still controversial, as some authors reported a reduced rate of VAP with early tracheostomy [8, 9, 22], while other studies could not confirm these observations [7, $20,23]$. In our SCI patients, we observed a high incidence of pneumonia, and the tracheostomy timing did not influence this rate. This is not surprising, as mechanical ventilation is only one of the risk factor for pneumonia in SCI, along with the severe impairment of tracheobronchial secretions clearance and high incidence of atelectasis. Moreover, the prevalence of pre-tracheostomy pneumonia is lower in ETG.

Our study also demonstrated that in LTG, the total number of complications is higher (observed in 52\% of cases) than in the ETG (31\% of cases) $(P<0.05$, Table 4$)$. Reported complications of tracheostomy are represented by hemorrhage, stoma infection, and mediastinitis in early phase, and later by granuloma, fistula and concentric tracheal stenosis [11, 14]. Those adverse effects have to be weighted against the risks of long-term intubation (edema, oral-labial ulceration, and laryngeal or tracheal stenosis). From our study, we found that SCI patients who underwent late tracheostomy had higher complications rate compared with patients with early tracheostomy, mainly due to incidence [24] of stenosis and granuloma, since the frequency of the other complications had been similar in both groups.

We conclude that the early tracheostomy is beneficial in SCI patients in terms of improving clinical management aspects, such as shortening the time of mechanical ventilation, reducing ICU stay, and lowering rates in complications of severe orotracheal intubation (e.g., tracheal granulomas and concentric tracheal stenosis). On the other hand, we could not demonstrate that early tracheostomy avoids the risk of VAP. We observed a trend towards reduced mortality that approached significance, and suggest that more studies employing a greater number of participants are needed on this important topic. On the basis of benefits demonstrated in this retrospective study, we then suggest to place tracheostomy as soon as possible in SCI patients who are likely to require prolonged mechanical ventilation.

\section{References}

1. Rana S, Pendem S, Pogodzinski MS, Hubmayr RD, Gajic O (2005) Tracheostomy in critically ill patients. Mayo Clin Proc 80:1632-1638

2. Jaeger JM, Littlewood KA, Durbin CG Jr (2002) The role of tracheostomy in weaning from mechanical ventilation. Respir Care 47:469-480

3. Harrop JS, Sharan AD, Scheid EH Jr, Vaccaro A, Przybylski GJ (2004) Tracheostomy placement in patients with complete cervical spinal cord injuries: American Spinal Injury Association Grade A. J Neurosurg (Spine 1) 100:20-23

4. Como JJ, Sutton ER, McCunn M, Dutton RP, Johnson SB, Aarabi B, Scalea TM (2005) Characterizing the need for mechanical ventilation following cervical spinal cord injury with neurological deficit. J Trauma 59:912-916

5. Plummer AL, Gracey DR (1989) Consensus conference on artificial airways in patients receiving mechanical ventilation. Chest 96:178-180

6. MacIntyre NR, Cook DJ, Ely EW Jr, et al., American College of Chest Physicians; American Association for Respiratory Care; American College of Critical Care Medicine (2001) Evidencebased guidelines for weaning and discontinuing ventilatory support: a collective task force facilitated by the American College of Chest Physicians; the American Association for Respiratory Care; and the American College of Critical Care Medicine. Chest 120(6 Suppl):375S-395S

7. Griffiths J, Barber VS, Morgan L, Young JD (2005) Systematic review and meta-analysis of studies of the timing of tracheostomy in adult patients undergoing artificial ventilation. BMJ 330:12431246

8. Moller MG, Slaikeu JD, Bonelli P, Davis AT, Hoogeboom JE, Bonnell BW (2005) Early tracheostomy versus late tracheostomy in the surgical intensive care unit. Am J Surg 189:293-296

9. Freeman BD, Borecki IB, Coopersmith CM, Buchman TG (2005) Relationship between tracheostomy timing and duration of mechanical ventilation in critically ill patients. Crit Care Med 33:2513-2520

10. Whited RE (1984) A prospective study of laryngotracheal sequelae in long term intubation. Laryngoscope 94:367-377

11. Friedman Y (1996) Indications, timing, techniques and complications of tracheostomy in the critically ill patient. Curr Opin Crit Care 2:47-53

12. Brook AD, Sherman G, Malen J, Kollef MH (2000) Early versus late tracheostomy in patients who require prolonged mechanical ventilation. Am J Crit Care 9:352-359

13. Jackson AB, Groomes TE (1994) Incidency of respiratory complications following spinal cord injury. Arch Phys Med Rehabil 75:270-275

14. Consortium for Spinal Cord Medicine (2005) Respiratory management following spinal cord injury: a clinical practice guideline for health-care professionals. J Spinal Cord Med 28:259-293

15. Brown R, DiMarco AF, Hoit JD, Garshick E (2006) Respiratory dysfunction and management in spinal cord injury. Respir Care 51:853-868

16. McWhorter AJ (2003) Tracheotomy: timing and techniques. Curr Opin Otolaringol Head Neck Surg 11:473-479

17. Kane TD, Rodriguez JL, Luchette FA (1997) Early versus late tracheostomy in the trauma patient. Respir Care Clin N Am $3: 1-20$ 
18. Flaaten H, Gjerde S, Heimdal JH, Aardal S (2006) The effects of tracheostomy on outcome in intensive care unit patients. Acta Anaesthesiol Scand 50:92-98

19. Goettler CE, Fugo JR, Bard MR, Newell MA, Sagraves SG, Toschlog EA et al (2006) Predicting the need for early tracheostomy: a multifactorial analysis of 992 intubated trauma patients. J Trauma 60:991-996

20. Dunham CM, Ransom KJ (2006) Assessment of early tracheostomy in trauma patients: a systematic review and meta-analysis. Am Surg 72:276-281

21. Frutos-Vivar F, Esteban A, Apezteguía C, Anzueto A, Nightingale P, Gonzalez $\mathrm{M}$ et al (2005) International Mechanical ventilation Study Group. Outcome of mechanically ventilated patients who require a tracheostomy. Crit Care Med 33:290-298
22. Arabi Y, Haddad S, Shirawi N, Shimemeri AA (2004) Early tracheostomy in intensive care trauma patients improves resource utilization: a cohort study and literature review. Crit Care 8:R347-R352

23. Sugerman HJ, Wolfe L, Pasquale MD, Rogers FB, O'Malley KF, Knudson M, DiNardo L, Gordon M, Schaffer S (1997) Multicenter, randomized, prospective trial of early tracheostomy. J Trauma 43:741-747

24. Zetouni A, Kost K (1994) Tracheostomy: a retrospective review of 281 cases. J Otolaryngol 23:61-66

25. Marino RJ, Barros T, Biering-Sørensen F, Burns SP, Donovan WH, Graves DE, et al. for ASIA Neurological Standards Committee 2002 (2003) International standards for neurological classification of spinal cord injury. J Spinal Cord Med 26(Suppl 1): S50-S56 